\title{
Prenatal exposure to lipopolysaccharide alters the intrarenal renin-angiotensin system and renal damage in offspring rats
}

\author{
Xue-Qin Hao ${ }^{1}$, Hai-Gang Zhang ${ }^{1}$, Zhi-Bing Yuan, Dan-Li Yang, Li-Yun Hao and Xiao-Hui Li
}

Prenatal exposure to inflammation produces offspring that are hypertensive in adulthood. This study explored alterations of the renin-angiotensin system (RAS) during the development of hypertension induced by prenatal exposure to lipopolysaccharide (LPS). In addition, the effects of an inhibitor of the nuclear transcription factor (NF)-kB (pyrrolidine dithiocarbamate, PDTC) on this process were assessed. Pregnant rats were randomly divided into four groups ( $n=8)$ : a control group, an LPS group, a PDTC group and an LPS+PDTC group. The rats in these groups were intraperitoneally administered vehicle, $0.79 \mathrm{mg} \mathrm{kg}^{-1} \mathrm{LPS}$, $100 \mathrm{mg} \mathrm{kg}^{-1}$ PDTC or LPS plus PDTC, respectively. LPS was given on the 8th, 10th and 12th days, whereas PDTC was given from the 8th to the 14th day during gestation. At various ages from day 1 to 25 weeks, plasma renin activity, plasma angiotensin II (Ang II) levels, renal function, glomerular number, mRNA expression levels of renal cortex renin and angiotensin-converting enzyme (ACE), the number of Ang II-positive cells and NF-кB activation were determined. The results showed that prenatal exposure to LPS resulted in significantly lower glomerular numbers and creatinine clearance rates and higher urinary protein and renal cortex ACE mRNA expression in adult offspring. Prenatal LPS also decreased the renal cortex renin mRNA expression and the number of Ang II-positive cells in offspring at 1 day of age, but these increased at 7, 16 and 25 weeks, whereas the plasma renin activity and Ang II concentration remained unchanged. Simultaneously, PDTC treatment markedly reversed the action of LPS. In conclusion, prenatal exposure to LPS resulted in alteration of the intrarenal RAS and renal damage in adult offspring rats. Hypertension Research (2010) 33, 76-82; doi:10.1038/hr.2009.185; published online 13 November 2009

Keywords: inflammation; offspring; prenatal stress; RAS

\section{INTRODUCTION}

The effects of hypertension on the cardiovascular and renal systems are of major concern due to its morbidity and mortality. Though many efforts have been made to understand the pathophysiology of hypertension, it is still unclear because of its complexity. ${ }^{1}$ A growing body of evidence indicates that hypertension is an inflammatory state wherein proinflammatory cytokines, such as tumor necrosis factor- $\alpha$ and interleukin-6, contribute to the hypertensive effect. ${ }^{2-5}$ Angiotensin II (Ang II), the major biologically active component of the reninangiotensin system (RAS), not only induces vasoconstriction, aldosterone release and sodium reabsorption by the nephron, but is also intricately interrelated with inflammation. Furthermore, the association of Ang II and inflammation induces an amplification process that involves oxidative stress and proinflammatory transcription factors, leading to progressive vascular injury ${ }^{6}$ and having an important role in the development of hypertension and target organ damage. ${ }^{2}$

It has been shown in our laboratory that maternal exposure to lipopolysaccharide (LPS) results in hypertension in offspring rats. ${ }^{7}$
However, the mechanisms are not well understood. Does RAS have a role in the development of hypertension programmed by prenatal exposure to LPS? This study was designed to test this hypothesis.

Lipopolysaccharide is a component of the cell wall of Gramnegative bacteria, and it acts as a nonspecific immunostimulant to mimic the bacterial inflammatory response. ${ }^{8}$ LPS initiates a series of phosphorylation events by binding to Toll-like receptor 4 and promoting the translocation of nuclear transcription factor $(\mathrm{NF})-\kappa \mathrm{B}$ into the nucleus. NF- $\kappa \mathrm{B}$ is a central regulator in immunological and inflammatory processes. ${ }^{9} \mathrm{NF}-\kappa \mathrm{B}$ family proteins exist in the cytoplasm of mammalian cells in an inactive state as heterotrimers, generally consisting of an inhibitory subunit, I $\mathrm{B}$, and other proteins, including p50, p65 (Rel A), Rel B and c-Rel. When the cell is activated by diverse proinflammatory stimuli, the upstream I-kappa kinase

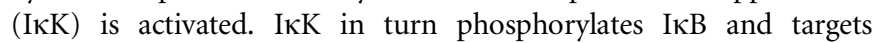
it for proteosomal degradation. The released dimer, most commonly the p50/p65 heterodimer, then translocates to the nucleus, where $\mathrm{NF}-\kappa \mathrm{B}$ promotes transcription of tumor necrosis factor- $\alpha$,

Institute of Materia Medica and Department of Pharmaceutics, College of Pharmacy, Third Military Medical University, Chongqing, China

${ }^{1}$ These authors contributed equally to this work.

Correspondence: Professor X-H Li, Institute of Materia Medica and Department of Pharmaceutics, College of Pharmacy, Third Military Medical University, Chongqing 400038, China.

E-mail: Ipsh008@yahoo.com.cn

Received 9 July 2009; revised 2 September 2009; accepted 8 October 2009; published online 13 November 2009 
interleukin-1 $\beta$ and interleukin- 6 and ultimately induces the inflammatory response. ${ }^{10,11}$

Pyrrolidine dithiocarbamate (PDTC), a synthetic antioxidant, inhibits NF- $\kappa \mathrm{B}$ by preventing I $\mathrm{B}$ degradation and the translocation of the active form to the nucleus. ${ }^{12}$ Various studies have shown that PDTC can prevent hypertension in spontaneous hypertensive rats and ameliorate Ang II-induced inflammation damage in rats. ${ }^{13,14}$ In this study, we duplicated the hypertensive rat model induced by prenatal exposure to LPS to explore the role of RAS and NF- $\mathrm{BB}$ in the development of hypertension.

\section{METHODS}

\section{Animals}

Nulliparous pregnant time-mated Sprague-Dawley rats were purchased from the Animal Centre of the Third Military Medical University (Chongqing, China). All animals had free access to standard laboratory rat chow and tap water. Until parturition, rats were housed individually in a room at constant temperature $\left(24^{\circ} \mathrm{C}\right)$ and under a 12-h light-dark cycle. Pups were raised with a lactating mother until 4 weeks of age, at which time they were removed to cages containing four rat pups. ${ }^{7}$ This study was conducted in accordance with the principles outlined in the National Institutes of Health Guide for the Care and Use of Laboratory Animals (http://grants1.nih.gov/grants/olaw/) and was approved by the local animal ethics committee at the Third Military Medical University

\section{Dams and litters}

Timed pregnant rats arrived at our institution at least 2 days before the initiation of the study. After 2 days of acclimation, the pregnant rats were randomly divided into four groups ( $n=8$ in each): a control group, an LPS group, a PDTC group and an LPS+PDTC group. The rats in these groups were intraperitoneally administered vehicle, $0.79 \mathrm{mg} \mathrm{kg}^{-1}$ LPS (Sigma Chemical, St Louis, MO, USA), $100 \mathrm{mg} \mathrm{kg}^{-1}$ PDTC (Sigma Chemical) or LPS plus PDTC, respectively. LPS was given on the 8 th, 10th and 12th days, whereas PDTC was given from the 8 th to the 14th day during gestation. The rats in the LPS group were given a vehicle injection on days $9,11,13$ and 14, and rats in the control group were given one every day during days 8-14. After delivery, the litter size was reduced to eight for each lactating mother. Neonatal rats were cared for by their mothers until they were weaned, after which they were then placed on standard rat chow. ${ }^{15}$ As it has been found that all offspring with prenatal exposure to LPS had elevated systolic blood pressure (SBP) from the age of 6 to 24 weeks, ${ }^{7}$ both male and female offspring rats were studied. Four males and four females from each group were randomly selected for future use in this study. The pregnant rats were used only once.

\section{Blood pressure measurement}

Systolic blood pressure was measured in eight conscious offspring rats in each group at 7, 10,13,16, 19, 22 and 25 weeks of age using the standard tail-cuff method $^{7}$ (ML125; Powerlab, ADInstruments, Castle Hill, NSW, Australia). Before measurement of SBP, rats were placed inside a warming chamber $\left(\sim 34^{\circ} \mathrm{C}\right)$ for $15 \mathrm{~min}$ and were then placed in plastic restraints. A cuff with a pneumatic pulse sensor was attached to the tail. In each rat, mean SBP was calculated from three consecutive SBP recordings. The rats had been trained at least three times before formal measurement.

\section{Urine, blood and kidney sample collection}

Offspring rats at 7, 16 and 25 weeks of age were kept in metabolic cages for 24-h urine collection when the rats were still fed standard rat chow. Then animals were anesthetized with sodium phenobarbital $\left(40 \mathrm{mg} \mathrm{kg}^{-1}\right)$, and blood was collected from the abdominal aorta. Then animals were killed, and the kidneys were abscised.

\section{Renal function analysis}

Plasma and urinary creatinine concentration were measured by multichannel kinetic spectrophotometry. ${ }^{16}$ Urinary protein level was determined using a spectrophotometric sequential injection method. ${ }^{17}$ Creatinine clearance rate was calculated using the following formula:

Creatinine clearance rate $\left(\mathrm{ml} \mathrm{min}^{-1}\right)=\frac{\text { urinary creatinine } \times 24 \text {-h urinary volume }}{\text { plasma creatinine } \times 1.44}$

\section{Glomerular number determination}

Glomerular number was determined using a technique previously described. ${ }^{15}$ Rats (7-week-old) were infused with $2 \mathrm{ml} \mathrm{kg}^{-1}$ alcian blue (5\%, w/v, Shanghai Sangon company, Shanghai, China) within $1 \mathrm{~min}$ through an abdominal aorta catheter placed above the renal arteries. A second $2 \mathrm{ml} \mathrm{kg}^{-1}$ bolus of alcian blue was then administered within 5-7 min after the first infusion. After $5 \mathrm{~min}$, the kidneys were removed, sliced in half and incubated in $5 \mathrm{ml}$ of $27 \%$ ammonia for $2 \mathrm{~h}$ at room temperature. Kidney samples were then incubated in $5 \mathrm{ml}$ of $8 \mathrm{~N}$ $\mathrm{HCl}$ at $50{ }^{\circ} \mathrm{C}$ for $1 \mathrm{~h}$. The suspension was diluted to a final volume of $20 \mathrm{ml}$ with water and incubated overnight at $4{ }^{\circ} \mathrm{C}$. The number of glomeruli in $30 \mu \mathrm{l}$ samples was counted using a light microscope and averaged from 10 samples to determine the number of glomeruli per kidney.

\section{Real-time PCR}

The renal cortex renin and angiotensin-converting enzyme (ACE) mRNA expression were assessed by real-time PCR when the offspring were at 1 day, 7,16 and 25 weeks of age, according to a method previously described. ${ }^{18}$ Total RNA was extracted from kidneys using Trizol (Roche Molecular Biochemicals, Mannheim, Germany) and was quantified by measuring absorbance at $260 \mathrm{~nm}$. Total RNA $(1 \mu \mathrm{g})$ was then reverse-transcribed into cDNA using a First Stand cDNA Synthesis Kit (Toyobo, Biochemical Operations Department, Osaka Japan) with Thermo Hybaid Px2 thermal cycler (Thermo, Franklin, MA, USA). $\beta$-Actin was used as an internal control. The PCR primers used were designed by Premier 5.0 (PREMIER Biosoft International, Palo Alto, CA, USA) based on the published nucleotide sequences for rat renin (forward: $5^{\prime}$ GGGTGCTAAAGGAGGAAGTGTT- ${ }^{\prime}$; reverse: $5^{\prime}$-AGTGAAAGTTGCCCTGG TAATG-3'); rat ACE (forward: 5'-TCCACCGTTACCAGACAACTATCC-3'; reverse: $5^{\prime}$-CTGCGTATTCGTTCCACAACACCT- $3^{\prime}$ ); rat $\beta$-actin (forward: $5^{\prime}$ GACGTTGACATCCGTAAAGACC-3'; reverse: $5^{\prime}$-TAGGA GCCAGGGCAGT AATCT- $3^{\prime}$ ). Each real-time PCR reaction was carried out in a total volume of $20 \mu \mathrm{l}$ with Quanti Tect SYBR Green PCR Master Mix (MJ Research, Waltham, MA, USA) according to the following conditions: $2 \mathrm{~min}$ at $95^{\circ} \mathrm{C}$, 40 cycles at $95^{\circ} \mathrm{C}$ for $10 \mathrm{~s}, 59^{\circ} \mathrm{C}$ (renin, $\beta$-actin), $61.5^{\circ} \mathrm{C}$ (ACE) for $15 \mathrm{~s}, 72^{\circ} \mathrm{C}$ for $20 \mathrm{~s}$, using the ABI Prism 7700 sequence detection system (ABI, Oyster Bay, NY, USA). After amplification, a melting curve analysis was carried out by collecting fluorescence data while increasing the temperature from $65^{\circ} \mathrm{C}$ to $99^{\circ} \mathrm{C}$ over $135 \mathrm{~s}$. The cycle threshold $\left(C_{\mathrm{t}}\right)$ values were normalized to the expression levels of $\beta$-actin.

\section{Plasma renin activity and Ang II concentration determination}

Blood was collected from the abdominal aorta when offspring were at 7, 16 and 25 weeks of age. Plasma renin activity and Ang II were measured by radioimmunoassay determination ${ }^{19-21}$ using the Angiotensin I and Angiotensin II Radioimmunoassay Kits (Beijing North Biological Technology, Beijing, China), respectively.

\section{EMSA}

An electrophoretic mobility shift assay (EMSA) was carried out in kidneys from rats at 25 weeks of age. Tissue extracts and EMSA for the transcription factor NF-kB were carried out as previously described. ${ }^{13}$ Nucleoprotein was extracted using the Nuclear and Cytoplasmic Protein Extraction Kit (Beyotime Institute of Biotechnology, Suzhou, China). Briefly, $100 \mathrm{mg}$ of frozen kidney tissue was pulverized and added to $1000 \mu \mathrm{l}$ of iced buffer A $\left(10 \mathrm{mmoll}^{-1} \mathrm{KCl}\right.$, $1.5 \mathrm{mmoll}^{-1} \quad \mathrm{MgCl}_{2}, \quad 1 \mathrm{mmoll}^{-1}$ dithiothreitol, $0.2 \mathrm{mmoll}^{-1}$ EDTA, $1 \mathrm{mmoll}^{-1} \mathrm{PMSF}$, $5 \%$ glycerol, $3 \mathrm{mgl}^{-1}$ aprotinin, $3 \mathrm{mgl}^{-1}$ phenanthroline, $1 \% \mathrm{NP} 40$ and $10 \mathrm{mmol}^{-1}$ HEPES) for $15 \mathrm{~min}$ and centrifuged $(16000 \mathrm{~g}$, $\left.15 \mathrm{~min}, 4^{\circ} \mathrm{C}\right)$. Then the deposit was added to $500 \mu \mathrm{l}$ of iced buffer $\mathrm{B}$ (420 $\mathrm{mmoll}^{-1} \mathrm{NaCl}, \quad 1.5 \mathrm{mmoll}^{-1} \quad \mathrm{MgCl}_{2}, 0.5 \mathrm{mmoll}^{-1}$ dithiothreitol, $0.2 \mathrm{mmoll}^{-1}$ EDTA, $0.5 \mathrm{mmoll}^{-1}$ PMSF, $25 \%$ glycerol, $5 \mathrm{mgl}^{-1}$ aprotinin, $5 \mathrm{mgl}^{-1}$ phenanthroline, $3 \mathrm{mgl}^{-1}$ pepstatin A and $20 \mathrm{mmoll}^{-1}$ HEPES), mixed well and put on ice for $10 \mathrm{~min}$. The process was repeated four times, and then 
the mixture was centrifuged again $\left(16000 \mathrm{~g}, 15 \mathrm{~min}, 4^{\circ} \mathrm{C}\right)$. The supernatant was divided into aliquots and frozen in liquid nitrogen until use. The protein concentration was quantified by the Bradford method. EMSAs were carried out using a commercial kit (Gel Shift Assay System, Promega, Madison, WI, USA). The NF- $\kappa B$ consensus oligonucleotide probe (5-AGTTGAGGGGACTTTCCCA GGC-3) was end-labeled with $\left[\gamma_{-}{ }^{32} \mathrm{P}\right]$ ATP (Free Biotech, Beijing, China) and T4-polynucleotide kinase. Then, $6.8 \mu \mathrm{g}$ of nuclear extract was incubated with a $\gamma-{ }^{32}$ P-labeled double-stranded oligonucleotide probe in $15 \mu$ of DNA-binding buffer containing $1 \mathrm{moll}^{-1}$ Tris- $\mathrm{HCl}$ (pH8.0), $1 \mathrm{moll}^{-1} \mathrm{NaOH}, 0.5 \mathrm{moll}^{-1}$ EDTA (pH 8.0), $1 \mathrm{moll}^{-1}$ dithiothreitol, and $1 \mathrm{moll}^{-1} \mathrm{MgCl} 2$, glycerol, poly $(\mathrm{dI}-\mathrm{dC})\left(1 \mu \mathrm{g} \mu \mathrm{l}^{-1}\right)$. The binding reaction was carried out at $37^{\circ} \mathrm{C}$ for $30 \mathrm{~min}$ in a total volume of $25 \mu$ l. Electrophoresis was carried out on a $4 \%$ native polyacrylamide gel at $200 \mathrm{~V}$ for $2 \mathrm{~h}$. The specificity of the binding reaction was examined by competitive analysis with a 100 -fold excess of unlabeled oligonucleotide probe and NF- $\mathrm{KB}$ p65antibody (Beyotime Institute of Biotechnology).

\section{Immunohistochemistry}

Intrarenal Ang II-positive cells were identified by immunohistochemical (IHC) staining as previously reported. ${ }^{21,22}$ The kidneys were incubated in $4 \%$ paraformaldehyde for $24 \mathrm{~h}$ and embedded in paraffin wax. The sections $(4 \mu \mathrm{m})$ were rinsed and rehydrated in phosphate-buffered saline (PBS) for $5 \mathrm{~min}$. An indirect immunoperoxidase staining technique was performed using the two-step IHC Detection reagent (Beijing Zhongshan Golden Bridge Biotechnology, Beijing, China). Briefly, endogenous peroxidase was inhibited by treatment with $3 \% \mathrm{H}_{2} \mathrm{O}_{2}$ in PBS for $15 \mathrm{~min}$. Then, blocking solution with $5 \%$ bovine serum albumin was applied to the sections for $15 \mathrm{~min}$ at room temperature to avoid nonspecific binding of the biotinylated antibody. The sections were incubated overnight at $4{ }^{\circ} \mathrm{C}$ for $12 \mathrm{~h}$ with primary rabbit anti-Ang-II antibody (Chemicon International, Temecula, CA, USA). Labeling was identified by application of a goat anti-rabbit IgG/horseradish peroxidase secondary antibody (Beijing Zhongshan Golden Bridge Biotechnology) at $37^{\circ} \mathrm{C}$ for 30 min. Peroxidase activity was visualized using a DAB kit (Boster Biological Engineering, Wuhan, China). The reaction was stopped by rinsing in PBS. Finally, the slides were dehydrated, mounted in an aqueous-based mounting medium and examined by light microscopy. The number of Ang II-positive cells in 20 fields of tubular interstitium at high magnification was counted using Image-Pro Plus software (Media Cybernetics, Silver Spring, MD, USA). ${ }^{23}$

\section{Statistical analysis}

Values are expressed as means \pm s.e.m. One-way analysis of variance and Tukey's post hoc test were used for all analyses; $P<0.05$ was considered significant. All analyses were carried out with SPSS 13.0 (SPSS Inc., Chicago, IL, USA).

\section{RESULTS}

\section{Dams and litters}

There was no significant difference in the mean number of progeny between control and LPS-treated dams $(10.7 \pm 0.81$ vs. $10.1 \pm 0.88$; $P>0.05)$. In addition, the ratio of male births to total births in each litter did not differ significantly between the control and LPS groups ( $0.50 \pm 0.11$ vs. $0.53 \pm 0.08 ; P>0.05)$, nor did the body weights of the newborn pups differ significantly between the control and LPS groups (male, $6.0 \pm 0.28$ vs. $6.2 \pm 0.25, P>0.05$; female, $6.1 \pm 0.14$ vs. $6.3 \pm 0.14, P>0.05)$.

\section{SBP in adult offspring}

Blood pressure in rat offspring from 7 to 25 weeks of age was measured once every 3 weeks, and the mean SBP of offspring in the LPS group was found to be significantly higher than that in the control group and the LPS+PDTC group. At 25 weeks of age, the mean SBP of offspring in the LPS group had reached $142.4 \mathrm{~mm} \mathrm{Hg}$, which was significantly higher than that in the control and LPS+PDTC groups. There was no significant difference between the controls and the offspring of PDTC-treated rats (Figure 1).

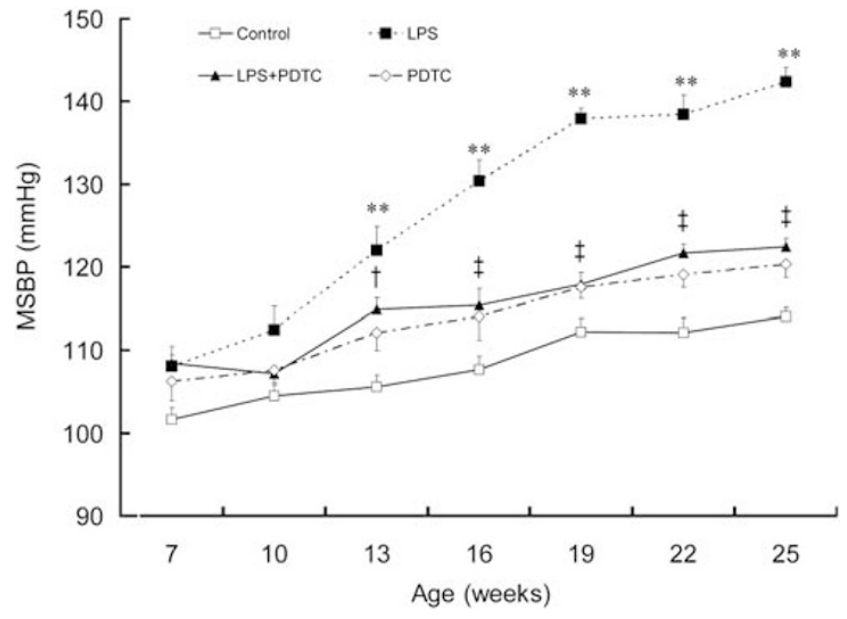

Figure 1 Prenatal exposure to lipopolysaccharide (LPS) influences systolic blood pressure (SBP) in offspring rats. Pregnant rats were randomly divided into four groups ( $n=8$ in each): control, LPS, pyrrolidine dithiocarbamate (PDTC) and LPS+PDTC groups. The rats in these groups were intraperitoneally administered vehicle, $0.79 \mathrm{mg} \mathrm{kg}^{-1} \mathrm{LPS}, 100 \mathrm{mg} \mathrm{kg}^{-1}$ PDTC or LPS plus PDTC, respectively. LPS was given on the 8th, 10th and 12th days, whereas PDTC was given from the 8th to the 14th day during gestation. SBP in the offspring was measured using the standard tail-cuff method. Data are presented as the mean \pm s.e.m. ( $n=8$ in each group). ${ }^{* *} P<0.01$ compared with controls; ${ }^{\dagger} P<0.05$ and $\ddagger P<0.01$ compared with offspring of LPS-treated rats. There was no significant difference between controls and offspring of PDTC-treated rats (one-way analysis of variance).

\section{Creatinine clearance rate in offspring rats}

The creatinine clearance rate in the offspring of LPS-treated rats was lower than that in the controls at 7, 16 and 25 weeks of age. PDTC treatment markedly increased the creatinine clearance rate at 16 and 25 weeks of age and increased it by $18 \%$ at 7 weeks of age. There was no significant difference between the controls and the offspring of PDTC-treated rats except at 7 weeks of age (Table 1).

\section{Urinary protein level in offspring rats}

The urinary protein level in the offspring of LPS-treated rats was higher than that in the controls at 7, 16 and 25 weeks of age. PDTC treatment markedly reduced the urinary protein level at 16 and 25 weeks of age and reduced it by $21 \%$ at 7 weeks of age. There was no significant difference between the controls and the offspring of PDTCtreated rats (Table 1).

\section{Number of glomeruli in offspring rats}

The number of glomeruli was determined in offspring at 7 weeks of age. The number of glomeruli in the offspring of LPS-treated rats was significantly lower than in the controls, and this was markedly reversed by PDTC treatment (Figure 2).

\section{mRNA levels of renin and ACE in kidney}

Compared with controls, the renal cortex renin mRNA expression was much lower in newborn offspring but higher in 7-, 16- and 25-weekold offspring of LPS-treated rats. Renin mRNA expression in the controls was much higher at 1 day of age but markedly lower at 7 weeks of age up until 25 weeks of age; by contrast, renin mRNA expression in the offspring of LPS-treated rats was low at 1 day of age but increased steadily with age (Figure 3 ). There was no significant difference in the ACE mRNA expression between newborn rats and 7- and 16-week-old rats. However, in 25-week-old rats, ACE mRNA 
Table 1 Effects of prenatal exposure to lipopolysaccharide on creatinine clearance rate and urinary protein level in offspring rats

\begin{tabular}{|c|c|c|c|c|c|c|c|}
\hline \multirow[b]{2}{*}{ Group } & \multirow[b]{2}{*}{ Dose $\left(m g g^{-1}\right)$} & \multicolumn{3}{|c|}{ Creatinine clearance rate $\left(\mathrm{m} / \mathrm{min}^{-1}\right)$} & \multicolumn{3}{|c|}{ Urinary protein (mg 24h-1) } \\
\hline & & 7 weeks & 16 weeks & 25 weeks & 7 weeks & 16 weeks & 25 weeks \\
\hline Control & - & $0.56 \pm 0.05$ & $2.37 \pm 0.18$ & $2.20 \pm 0.17$ & $4.63 \pm 0.40$ & $12.34 \pm 1.70$ & $13.35 \pm 2.33$ \\
\hline LPS & 0.79 & $0.35 \pm 0.05^{*}$ & $1.10 \pm 0.23^{* *}$ & $1.04 \pm 0.17^{* *}$ & $7.12 \pm 1.02^{*}$ & $19.92 \pm 2.59^{*}$ & $38.25 \pm 2.10^{* *}$ \\
\hline LPS+PDTC & $0.79+100$ & $0.43 \pm 0.03$ & $1.88 \pm 0.23^{\dagger}$ & $2.16 \pm 0.15^{\ddagger}$ & $5.63 \pm 0.73$ & $10.31 \pm 1.69 \ddagger$ & $23.97 \pm 2.08^{\ddagger}$ \\
\hline PDTC & 100 & $0.37 \pm 0.03^{* *}$ & $2.42 \pm 0.21$ & $1.89 \pm 0.18$ & $6.04 \pm 0.95$ & $17.56 \pm 1.73$ & $16.02 \pm 2.68$ \\
\hline
\end{tabular}

Abbreviations: LPS, lipopolysaccharide; PDTC, pyrrolidine dithiocarbamate.

Data are presented as the mean \pm s.e.m. ( $n=8$ in each group).

${ }^{*} P<0.05,{ }^{* *} P<0.01$ compared with controls; ${ }^{\ddagger} P<0.01,{ }^{\dagger} P<0.05$ compared with the offspring of LPS-treated rats (one-way analysis of variance).

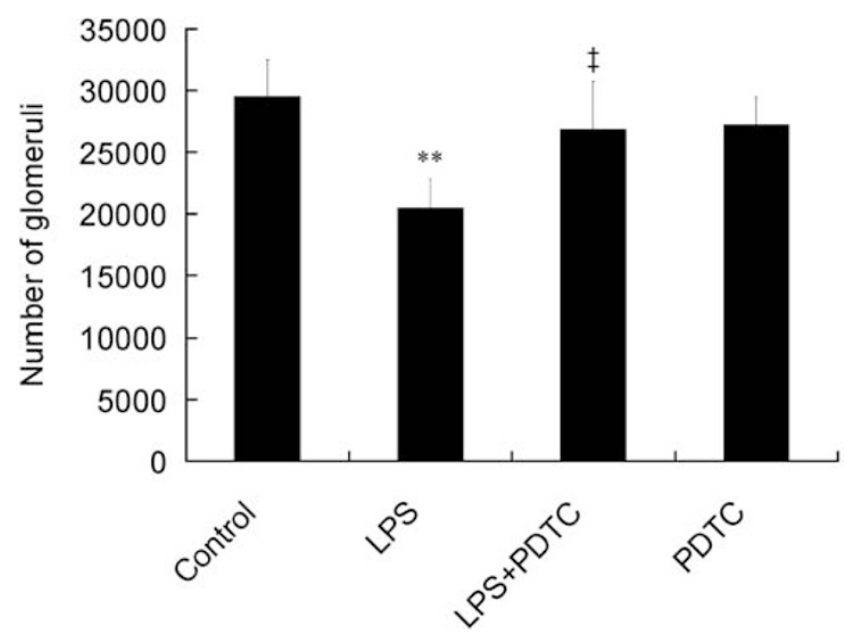

Figure 2 Effect of prenatal exposure to lipopolysaccharide (LPS) on the number of glomeruli in 7-week-old offspring rats. Data are presented as the mean \pm s.e.m. ( $n=8$ in each group). ${ }^{* *} P<0.01$ compared with controls; $\ddagger P<0.01$ compared with offspring of LPS-treated rats (one-way analysis of variance). PDTC, pyrrolidine dithiocarbamate.

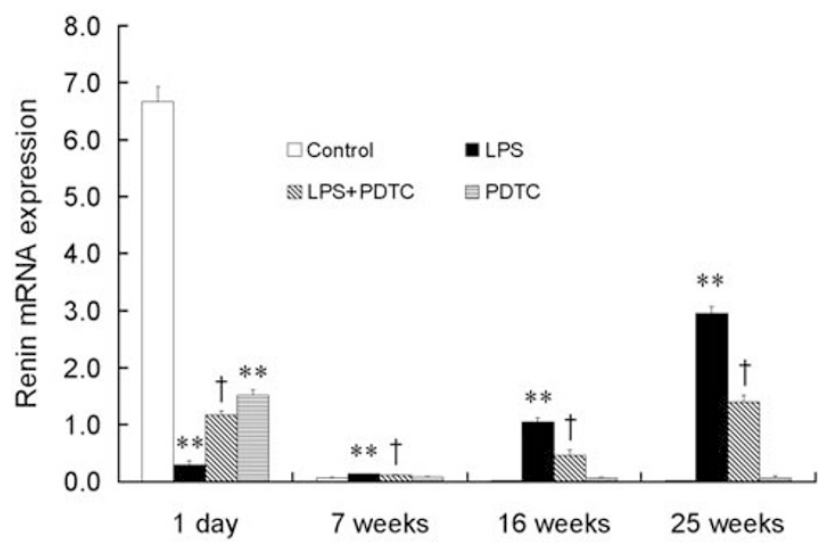

Figure 3 Effect of prenatal exposure to lipopolysaccharide (LPS) on renal cortex renin mRNA expression in offspring rats. Data are presented as the mean \pm s.e.m. ( $n=8$ in each group). ${ }^{* *} P<0.01$ compared with controls; ${ }^{\dagger} P<0.05$ compared with offspring of LPS-treated rats (one-way analysis of variance). PDTC, pyrrolidine dithiocarbamate.

expression increased dramatically in the offspring of LPS-treated rats compared with the controls $(1.596 \pm 0.110$ vs. $0.011 \pm 0.003$, $P<0.001)$. PDTC treatment markedly dampened the increase in renin (Figure 3) and ACE $(0.369 \pm 0.066$ vs. $1.596 \pm 0.110, P<0.001)$ mRNA expression.

Plasma renin activity and Ang II concentration

The relationships between the controls and the offspring of LPStreated rats with respect to renin activity and Ang II concentration at 7,16 and 25 weeks of age were as follows: renin activity $\left(\mathrm{ng} \mathrm{ml}^{-1} \mathrm{~h}^{-1}\right)$ $4.49 \pm 0.43 v s .5 .23 \pm 0.42$ at the 7 th week; $2.78 \pm 0.36 v s$. $3.40 \pm 0.49$ at the 16th week; and $3.16 \pm 0.64$ vs. $1.89 \pm 0.25$ at the 25 th week. Ang II concentration $\left(\mathrm{ng} \mathrm{ml}^{-1}\right) 1.937 \pm 0.082$ vs. $1.840 \pm 0.060$ at the 7 th week; $2.127 \pm 0.088$ vs. $1.924 \pm 0.126$ at the 16th week; and $2.387 \pm 0.080$ vs. $2.229 \pm 0.051$ at the 25 th week. There was no significant difference in the plasma renin activity or Ang II concentration among the groups at 7,16 or 25 weeks of age $(P>0.05)$.

\section{EMSA for NF-кB}

The EMSA for the transcription factor NF- $\kappa \mathrm{B}$ was carried out in

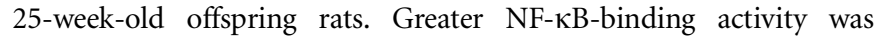
observed in the offspring of LPS-treated rats compared with both the controls and the offspring of (LPS+PDTC)-treated rats. The specific binding of NF- $\mathrm{KB}$ was confirmed by the addition of a 100 -fold excess of unlabeled NF- $\kappa \mathrm{B}$ competitor DNA into the EMSA reaction. Unlabeled NF- $\mathrm{BB}$ DNA competed for binding in the extracts prepared from kidney of the offspring of LPS-treated rats. The presence of NF- $\kappa \mathrm{B}$ in the protein complex was also shown by antibody supershift assays. The p65 antibody considerably shifted the major NF-кB-binding complexes (Figure 4).

\section{Ang II-positive cells in the kidney}

Microphotography showed that Ang II-positive cells were both proximal tubular cells and infiltrating interstitial immune cells (Figure 5a). The number of Ang II-positive cells in 20 fields of tubular area under high magnification was counted and averaged. Compared with the controls, the number of Ang II-positive cells in the offspring of LPStreated rats was significantly lower at 1 day of age but higher at 7, 16 and 25 weeks of age (Figure 5b), and this trend was markedly reversed by PDTC treatment.

\section{DISCUSSION}

The RAS is a hormonal cascade that functions in the homeostatic control of arterial pressure, tissue perfusion and extracellular volume. RAS is initiated by the regulated secretion of renin, which is the ratelimiting enzyme catalyzing the hydrolysis of Ang I from the $\mathrm{N}$-terminus of angiotensinogen. Ang I is in turn hydrolyzed by ACE to form Ang II, a potent vasoconstrictor and the primary active product of RAS. ${ }^{24}$ Ang II has an important role in the pathogenesis of cardiovascular and renal disorders. In addition, an intact RAS is 


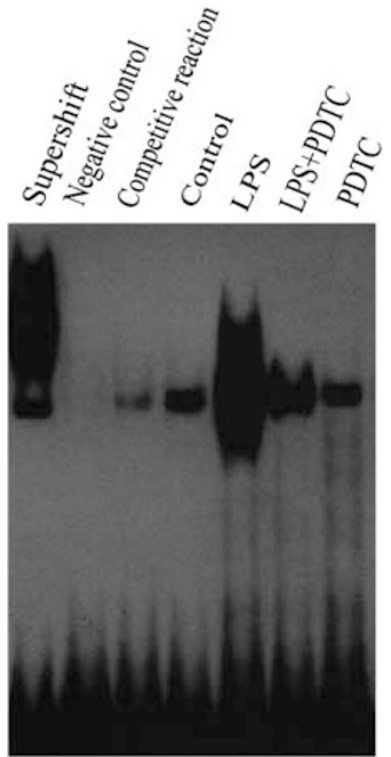

Figure 4 Electrophoretic mobility shift assay (EMSA) for the nuclear transcription factor (NF)- $\mathrm{kB}$ in kidney of rats at 25 weeks of age. Nuclear protein was extracted from the kidneys of 25-week-old rats. Binding reactions or EMSAs were carried out with an NF-kB oligonucleotide labeled with $\left[\gamma^{-32}\right]$ dATP ( $n=8$ in each group). Complex formation was further confirmed by supershift analysis by using p65 antibody. A cold competitor reaction was carried out using $100 \mathrm{ng}$ of unlabeled probe to compete with $1 \mathrm{ng}$ of labeled probe. EMSA for the detection of NF-KB showed higher binding activity in the kidney of offspring of lipopolysaccharide (LPS)-treated rats, and this was markedly reduced by pyrrolidine dithiocarbamate (PDTC) treatment.

essential for normal kidney development. ${ }^{25}$ Inadvertent use of ACE inhibitors or $\mathrm{AT}_{1}$ receptor blockers during pregnancy causes structural and functional developmental abnormalities of the kidney in the fetus. ${ }^{25,26}$

This study showed for the first time that prenatal exposure to LPS resulted in lower renal cortex renin mRNA expression in newborn rats, but higher renal cortex renin mRNA expression in 7-, 16- and 25week-old rats and higher ACE mRNA expression in 25-week-old rats. This could be explained if prenatal exposure to LPS suppressed the activity of RAS in fetal/newborn rats and in turn impaired renal development during pregnancy; the resulting lower number of glomeruli would result in higher RAS activity in adulthood. This result is supported by the previous study by Woods et al. ${ }^{27}$, who found that maternal protein restriction suppresses the newborn RAS and programs adult hypertension in rats.

However, the SBP of the offspring born from LPS-treated rats correlated with intrarenal RAS activity, not with plasma RAS activity. As the SBP increased persistently, the plasma renin activity and Ang II levels remained unchanged. This phenomenon is consistent with the observation of Franco et al. ${ }^{22}$ that blood pressure levels were negatively correlated with plasma Ang II and positively correlated with renal Ang II concentrations in a salt-sensitive hypertensive model. In addition, renal Ang II concentration has been correlated with the number of Ang II-positive cells and infiltrating immune cells. In this study, the Ang II-positive cells were both tubular cells and infiltrating immune cells, and the number of Ang II-positive cells was positively correlated with the renal cortex renin mRNA expression and blood pressure. This suggests that it is the intrarenal RAS that is contributing an important role in the development of hypertension.
The intrarenal Ang II levels are regulated in a manner distinct from circulating Ang II concentrations. In Ang II-dependent hypertension, $\mathrm{AT}_{1}$ receptor blockade increased plasma Ang II concentrations; however, it markedly limited the enhanced kidney Ang II contents elicited by chronic Ang II infusions. ${ }^{28}$ This dissociation between plasma Ang II and intrarenal Ang II shows differential regulation of Ang II in the kidney and in the circulation. This dissociation between plasma Ang II and intrarenal Ang II has also been observed in other hypertensive models. In the Page cellophane-wrapped kidney model, the cellophane-wrapped group had progressive increments in blood pressure and Ang II content in the kidney; the plasma levels of Ang II were similar in the cellophane-wrapped group and the sham-operated animals and were unchanged from baseline. ${ }^{29,30}$

In this study, prenatal exposure to LPS also resulted in reduced creatinine clearance rate and elevated urinary protein in 7-, 16- and 25 -week-old offspring rats. The reduced creatinine clearance rate may be attributable to the lower filtration area and the activated intrarenal RAS. Exogenous administration of Ang II elicits dose-dependent decreases in renal blood flow and glomerular filtration rate. ${ }^{31,32}$ In vivo micropuncture studies in rats also showed that Ang II elicits reductions in single nephron glomerular filtration rate and glomerular plasma flow and increases in both afferent and efferent arteriolar resistance. ${ }^{30,33-36}$ Furthermore, Ang II regulates vascular permeability through pressure-mediated mechanical injury of the endothelium and through direct nonhemodynamic effects; the latter occurs through local induction of the release of second mediators. Ang II stimulates synthesis of prostaglandins (PGs), such as $\mathrm{PGE}_{2}$ and $\mathrm{PGI}_{2}$, as well as leukotriene $\mathrm{C}_{4}$, and thereby modulates microvascular permeability. ${ }^{10}$ The filtration barrier of the kidney, the glomerulus, prevents plasma proteins from leaking into primary urine and comprises three layers: endothelial cells, glomerular basement membrane and visceral epithelial cells (podocytes). It has recently become accepted that the slit diaphragm located between adjacent foot processes of podocytes functions as the final barrier of the glomerular capillary wall. The Ang II treatment clearly reduced the mRNA expression of the critical molecules (nephrin, podocin and ZO-1) of the slit diaphragm both in vivo and in vitro. ${ }^{37} \mathrm{AT}_{1}$ receptor antagonist treatment ameliorated proteinuria by preventing a reduction in the functional molecules of the slit diaphragm. ${ }^{38,39}$ All these considerations provide support for our hypothesis that the proteinuria induced by prenatal exposure to LPS in this study may occur through the activation of intrarenal RAS.

Filtration barrier damage is associated with hypertension, and the degree of proteinuria was found to be a significant determinant of the presence of hypertension in the study population. Proteinuria is also a predictor for future development of hypertension among normotensive individuals. A cross-sectional study of 232 veterans affairs patients with chronic kidney disease showed degree of proteinuria to be the most significant correlate for SBP. Furthermore, increased arterial stiffness, as assessed by pulse wave velocity, was shown to be associated with the presence of dipstick-positive proteinuria, creatinine clearance and SBP in the general population of Okinawa, Japan $(n=3387){ }^{40}$ These data support the result of our study that the urinary protein level correlates with intrarenal RAS and blood pressure.

Nuclear transcription factor- $\kappa \mathrm{B}$ activation has an important role in Ang II-induced end-organ damage and hypertension. Ang II infusion results in a significant upregulation of NF- $\kappa \mathrm{B}, \mathrm{RAS}$, proinflammatory cytokines and oxidative stress, and the interplay between RAS, proinflammatory cytokines and NF- $\kappa B$ leads to a sustained increase in oxidative stress, which contributes to the pathogenesis of hypertension. ${ }^{2}$ It was found in this study that the most effective inhibitor of 
a
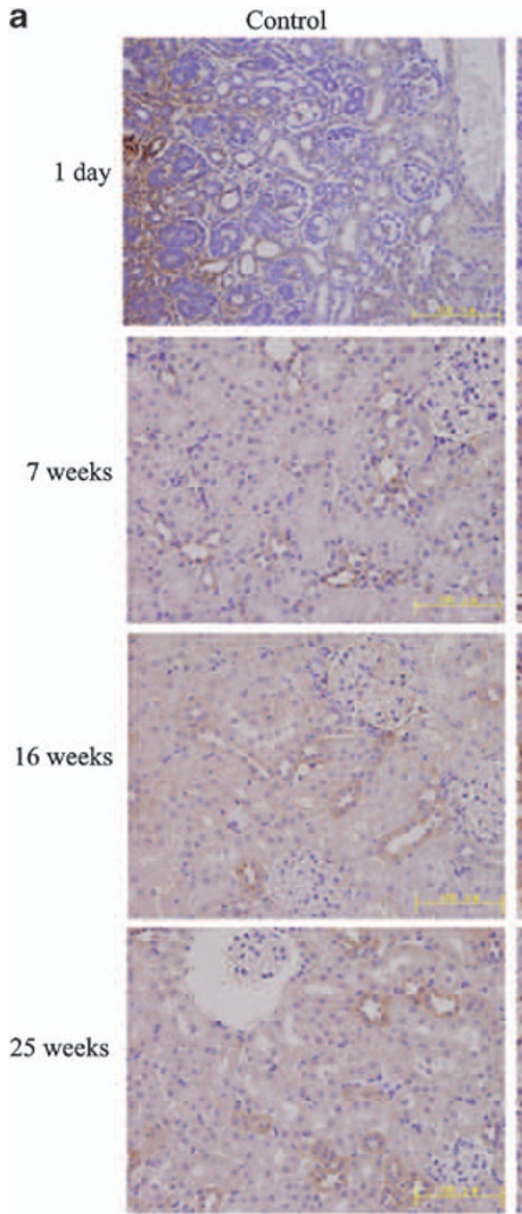

LPS
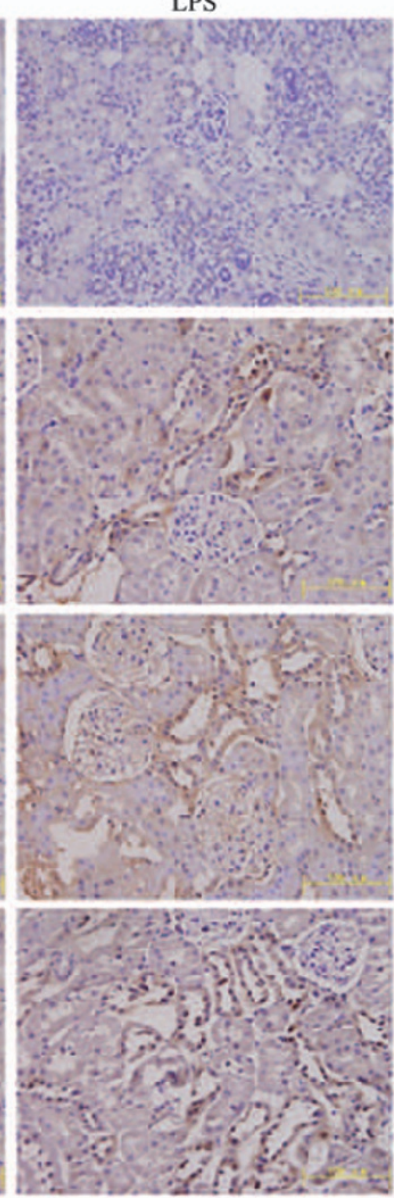

LPS+PDTC
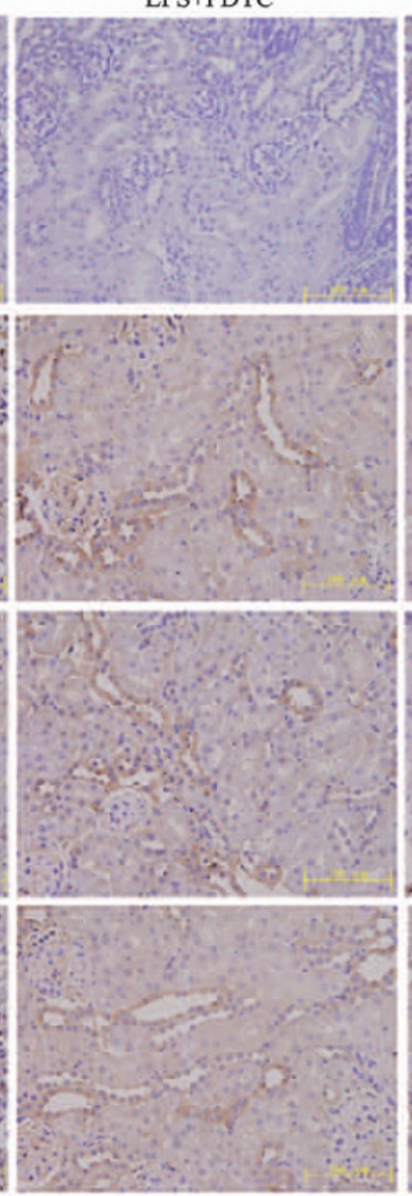

PDTC
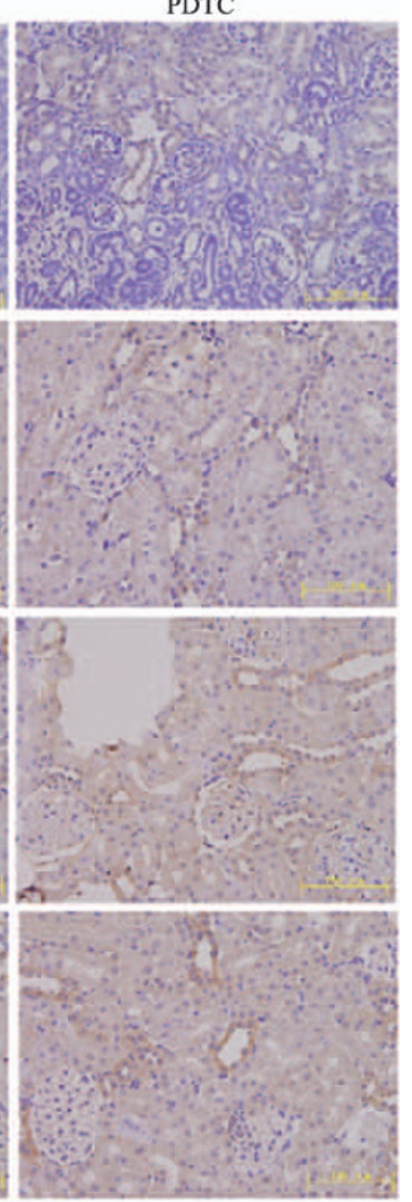

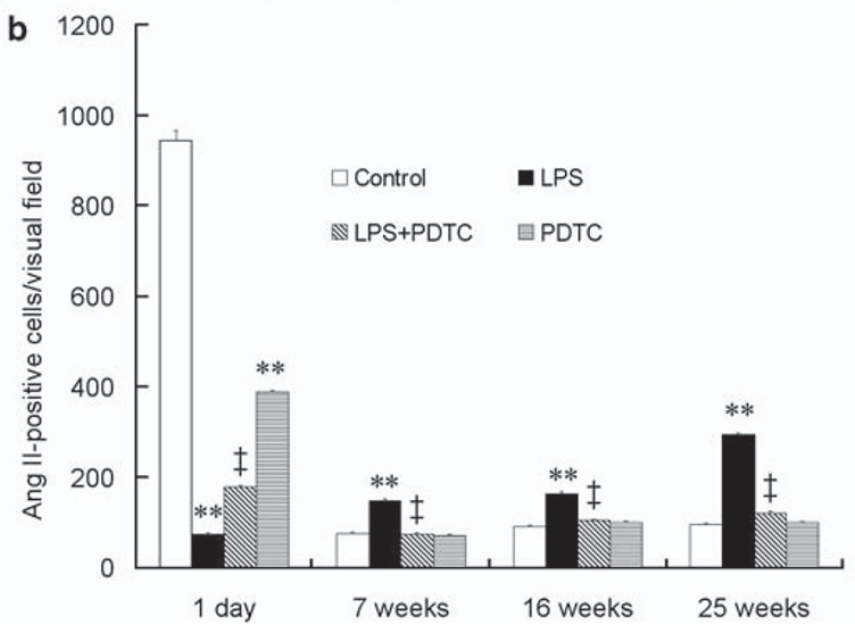

Figure 5 Effect of prenatal exposure to lipopolysaccharide (LPS) on the number of renal cortex angiotensin II (Ang II)-positive cells in offspring rats. (a) Immunohistochemistry analysis $(\mathrm{bar}=100 \mu \mathrm{m})$ : Ang II-positive cells were both proximal tubular cells and infiltrating interstitial immune cells. (b) Histograms represent the number of Ang II-positive cells per visual field. The Ang II-positive cells of 20 fields of tubular area at high magnification were counted and averaged. Data are presented as the mean \pm s.e.m. ( $n=8$ in each group). ${ }^{* *} P<0.01$ compared with controls; ${ }^{\ddagger} P<0.01$ compared with offspring of LPS-treated rats (one-way analysis of variance). PDTC, pyrrolidine dithiocarbamate.

NF- $\kappa B$, PDTC, markedly reduced the DNA-binding activity of NF- $\kappa B$ in 25-week-old offspring of LPS-treated rats, leading to a nearly complete reversal in renal function and a partial reverse in blood pressure. Therefore, it is possible that the decrease in blood pressure might have resulted from the improvement in renal function.
In conclusion, prenatal exposure to LPS resulted in reduced intrarenal RAS activity in newborn offspring rats and elevated RAS activity in adulthood. In addition, prenatal exposure to LPS caused renal damage in offspring rats. NF- $\mathrm{KB}$ might be involved in the hypertension and renal damage induced by prenatal exposure to LPS. 


\section{ACKNOWLEDGEMENTS}

This research was supported by grants from the Natural Science Foundation of China (No. 30672641, No. 30470465), the National High Technology Research and Development Program of China (863 Program) (No. 2007AA10Z356) and from the Natural Science Foundation of Chongqing, China (No. 20048256).

1 Karthikeyan VJ, Lip GY. Oxidative stress and hypertension. Int J Clin Pract 2006; 60: 1525-1527.

2 Kang YM, Ma Y, Zheng JP, Elks C, Sriramula S, Yang ZM, Francis J. Brain nuclear factorkappa $\mathrm{B}$ activation contributes to neurohumoral excitation in angiotensin II-induced hypertension. Cardiovasc Res 2009; 82: 503-512.

3 Mauno V, Hannu K, Esko K. Proinflammation and hypertension: a population-based study. Mediators Inflamm 2008; 2008: 619704

4 Rizzo M, Corrado E, Coppola G, Muratori I, Novo G, Novo S. Markers of inflammation are strong predictors of subclinical and clinical atherosclerosis in women with hypertension. Coron Artery Dis 2009; 20: 15-20.

5 Pauletto P, Rattazzi M. Inflammation and hypertension: the search for a link. Nephrol Dial Transplant 2006; 21: 850-853.

6 Marchesi C, Paradis P, Schiffrin EL. Role of the renin-angiotensin system in vascular inflammation. Trends Pharmacol Sci 2008; 29: 367-374.

7 Wei YL, Li XH, Zhou JZ. Prenatal exposure to lipopolysaccharide results in increases in blood pressure and body weight in rats. Acta Pharmacol Sin 2007; 28: 651-656.

8 Liao W, Wei Y, Yu C, Zhou J, Li S, Pang Y, Li X. Prenatal exposure to zymosan results in hypertension in adult offspring rats. Clin Exp Pharmacol Physiol 2008; 35: 1413-1418.

9 Wu J, Yang X, Zhang YF, Zhou SF, Zhang R, Dong XQ, Fan JJ, Liu M, Yu XQ. Angiotensin II upregulates Toll-like receptor 4 and enhances lipopolysaccharide-induced CD40 expression in rat peritoneal mesothelial cells. Inflamm Res 2009; 58: 473-482. (e-pub ahead of print 7 March 2009).

10 Chan MY, Cross-Mellor SK, Kavaliers M, Ossenkopp KP. Lipopolysaccharide (LPS) blocks the acquisition of $\mathrm{LiCl}$-induced gaping in a rodent model of anticipatory nausea. Neurosci Lett 2009; 450: 301-305.

11 Guzik TJ, Harrison DG. Endothelial NF-kB as a mediator of kidney damage: the missing link between systemic vascular and renal disease? Circ Res 2007; 101: 227-229.

12 Messina S, Bitto A, Aguennouz M, Minutoli L, Monici MC, Altavilla D, Squadrito F, Vita G. Nuclear factor kappa-B blockade reduces skeletal muscle degeneration and enhances muscle function in Mdx mice. Exp Neurol 2006; 198: 234-241.

13 Muller DN, Dechend R, Mervaala EM, Park JK, Schmidt F, Fiebeler A, Theuer J, Breu V, Ganten D, Haller H, Luft FC. NF-kappaB inhibition ameliorates angiotensin II-induced inflammatory damage in rats. Hypertension 2000; 35: 193-201.

14 Rodriguez-Iturbe B, Ferrebuz A, Vanegas V, Quiroz Y, Mezzano S, Vaziri ND. Early and sustained inhibition of nuclear factor-kappaB prevents hypertension in spontaneously hypertensive rats. J Pharmacol Exp Ther 2005; 315: 51-57.

15 Ortiz LA, Quan A, Weinberg A, Baum M. Effect of prenatal dexamethasone on rat renal development. Kidney Int 2001; 59: 1663-1669.

16 Ohira S, Kirk AB, Dasgupta PK. Automated measurement of urinary creatinine by multichannel kinetic spectrophotometry. Anal Biochem 2009; 384: 238-244.

17 Kanchana WI, Sakai T, Teshima N, Katoh S, Grudpan K. Successive determination of urinary protein and glucose using spectrophotometric sequential injection method. Anal Chim Acta 2007; 604: 139-146.

18 Yuan ZB, Zhang HG, Jia Y, Cheng YQ, Li XH. Temporal expression of cyclooxygenase-2 in peritoneal macrophages of rats and effects of panax notoginseng saponins. Inflamm Res 2009; 58: 74-80.

19 Nishiyama A, Seth DM, Navar LG. Renal interstitial fluid concentrations of angiotensins I and II in anesthetized rats. Hypertension 2002; 39: 129-134.
20 Hoffmann S, Podlich D, Hahnel B, Kriz W, Gretz N. Angiotensin II type 1 receptor overexpression in podocytes induces glomerulosclerosis in transgenic rats. J Am Soc Nephrol 2004; 15: 1475-1487.

21 Nishiyama A, Seth DM, Navar LG. Renal interstitial fluid angiotensin I and angiotensin II concentrations during local angiotensin-converting enzyme inhibition. J Am Soc Nephrol 2002; 13: 2207-2212.

22 Franco M, Martinez F, Quiroz Y, Galicia O, Bautista R, Johnson RJ, Rodriguez-Iturbe B. Renal angiotensin II concentration and interstitial infiltration of immune cells are correlated with blood pressure levels in salt-sensitive hypertension. Am J Physiol Regul Integr Comp Physiol 2007; 293: R251-R256.

23 Pena LA, Fuks Z, Kolesnick RN. Radiation-induced apoptosis of endothelial cells in the murine central nervous system: protection by fibroblast growth factor and sphingomyelinase deficiency. Cancer Res 2000; 60: 321-327.

24 Atlas SA. The renin-angiotensin aldosterone system: pathophysiological role and pharmacologic inhibition. J Manag Care Pharm 2007; 13: 9-20.

25 Guron G, Molne J, Swerkersson S, Friberg P, Hansson S. A 14-year-old girl with renal abnormalities after brief intrauterine exposure to enalapril during late gestation. Nephrol Dial Transplant 2006; 21: 522-525.

26 Martinovic J, Benachi A, Laurent N, Daikha-Dahmane F, Gubler MC. Fetal toxic effects and angiotensin-II-receptor antagonists. Lancet 2001; 358: 241-242.

27 Woods LL, Ingelfinger JR, Nyengaard JR, Rasch R. Maternal protein restriction suppresses the newborn renin-angiotensin system and programs adult hypertension in rats. Pediatr Res 2001; 49: 460-467.

28 Kobori H, Prieto-Carrasquero MC, Ozawa Y, Navar LG. AT1 receptor mediated augmentation of intrarenal angiotensinogen in angiotensin II-dependent hypertension. Hypertension 2004; 43: 1126-1132.

29 Vanegas V, Ferrebuz A, Quiroz Y, Rodriguez-Iturbe B. Hypertension in Page (cellophanewrapped) kidney is due to interstitial nephritis. Kidney Int 2005; 68: 1161-1170.

30 Kobori H, Nangaku M, Navar LG, Nishiyama A. The intrarenal renin-angiotensin system: from physiology to the pathobiology of hypertension and kidney disease. Pharmacol Rev 2007; 59: 251-287.

31 Yamamoto $T$, Hayashi $K$, Matsuda $H$, Kubota E, Tanaka $H$, Ogasawara $Y$, Nakamoto $H$, Suzuki H, Saruta T, Kajiya F. In vivo visualization of angiotensin II and tubuloglomerular feedback-mediated renal vasoconstriction. Kidney Int 2001; 60: 364-369.

32 Paul M, Poyan Mehr A, Kreutz R. Physiology of local renin-angiotensin systems. Physiol Rev 2006; 86: 747-803.

33 Edgley AJ, Kett MM, Anderson WP. Evidence for renal vascular remodeling in angiotensin II-induced hypertension. J Hypertens 2003; 21: 1401-1406.

34 Sarkis A, Liu KL, Lo M, Benzoni D. Angiotensin II and renal medullary blood flow in Lyon rats. Am J Physiol Renal Physiol 2003; 284: F365-F372.

35 Badzyńska BG-MM. Differential effect of angiotensin II on blood circulation in the renal medulla and cortex of anaesthetized rats. J Physiol 2002; 538: 159-166.

36 Sorensen CM, Leyssac PP, Skott O, Holstein-Rathlou NH. Role of the renin-angiotensin system in regulation and autoregulation of renal blood flow. Am J Physiol Regul Integr Comp Physiol 2000; 279: R1017-R1024.

37 Suzuki K, Han GD, Miyauchi N, Hashimoto T, Nakatsue T, Fujioka Y, Koike H, Shimizu $\mathrm{F}$, Kawachi $\mathrm{H}$. Angiotensin II type 1 and type 2 receptors play opposite roles in regulating the barrier function of kidney glomerular capillary wall. Am J Pathol 2007; 170: $1841-1853$.

38 Liang XB, Ma LJ, Naito T, Wang Y, Madaio M, Zent R, Pozzi A, Fogo AB. Angiotensin type 1 receptor blocker restores podocyte potential to promote glomerular endothelial cell growth. J Am Soc Nephrol 2006; 17: 1886-1895.

39 Durvasula RV, Petermann AT, Hiromura K, Blonski M, Pippin J, Mundel P, Pichler R, Griffin S, Couser WG, Shankland SJ. Activation of a local tissue angiotensin system in podocytes by mechanical strain. Kidney Int 2004; 65: 30-39.

40 Agrawal V, Marinescu V, Agarwal M, McCullough PA. Cardiovascular implications of proteinuria: an indicator of chronic kidney disease. Nat Rev Cardiol 2009; 6: 301-311. 